\title{
NOTAS SOBRE LA CANCILLERÍA DEL ONCENO EN TIEMPOS DE MINORIDAD: A PROPÓSITO DE DOS CARTAS DE ALFONSO XI A LA ORDEN DE SANTIAGO ${ }^{1}$
}

\author{
Érika López Gómez \\ Universidad Autónoma de Madrid
}

\section{RESUMEN}

El estudio de la documentación de Alfonso XI ha sido una de nuestras principales áreas de investigación durante los últimos años. Su análisis pormenorizado nos ha permitido conocer a fondo la escritura de la primera mitad del siglo XIV, así como la actividad y funciones de la Cancillería real. Centramos nuestra atención en los diplomas depositados en la sección de Órdenes Militares del Archivo Histórico Nacional, de los cuales hemos creído conveniente revisar dos, emitidos durante el tiempo de las tutorías, por cuanto detectamos ciertos elementos susceptibles de realizar una crítica diplomática. Gracias a su examen, hemos podido establecer cuál era la práctica cancilleresca en aquel periodo cronológico y hemos comprobado que durante la menor edad del Onceno fueron frecuentes las corruptelas y mala praxis de quienes formaban parte de la principal oficina de expedición documental.

Palabras clave: Paleografía; Diplomática; Cancillería real; Alfonso XI; Archivo Histórico Nacional; órdenes militares; siglo XIV.

1 Abreviaturas utilizadas: AHN: Archivo Histórico Nacional; AMM: Archivo Municipal de Murcia; $\operatorname{carp}(\mathrm{s}) .: \operatorname{carpeta(s)}$; c.: cajón; $\operatorname{doc}(\mathrm{s}) .:$ documento(s); f., ff.: folio(s); Ibid., EAD., ID.: el/lo/la mismo/a; $\mathrm{n}^{\circ}, \mathrm{n}^{\text {os: }}$ número(s); OM: Órdenes Militares; p., pp.: página(s); s.l.: sin lugar de edición; RAH: Real Academia de la Historia. 


\section{ABSTRACT}

The study of Alfonso XI's documentation has been one of the our most important research area for the last few years. His detailed analysis that allowed us to have a good knowledge about the scripts of the first half of XIV $^{\text {th }}$ Century and, also, the activity and functions of the Royal Chancellery. We focus our attention on letters kept in Military Orders' section of the National Historical Archive, because we have considered that was appropiate to review both of them, issues during mentoring time, as we have detected some susceptibles elements to realised a diplomatic criticize. Due to their exam, we have established how was the Chancellery practice in this chronological period and we have test that, during the younger age of Alfonso $\mathrm{XI}$, the corruptions and the malpractice was common in the members of the central office of documental expedition.

Keywords: Palaeography; Diplomatic; Royal Chancellery; Alfonso XI; National Historical Archive; Military Orders; XIV ${ }^{\text {th }}$ Century.

\section{INTRODUCCIÓN}

En fechas recientes, el análisis de la Cancillería real de Alfonso XI ha ocupado cuantiosas páginas en revistas y libros. Martín Postigo, además de ser la pionera en la elaboración de un estado de la cuestión sobre esta oficina de expedición documental, publicó un breve estudio dedicado a la Notaría mayor de los privilegios rodados, culminación de la escribanía mayor del mismo nombre que se pergeña en estos años ${ }^{2}$. Significativas son, asimismo, las obras de Ostolaza Elizondo, nuestro principal referente, ya que aportan interesantes datos sobre el objeto de estudio ${ }^{3}$. También resultan de utili-

2 MARTÍN POSTIGO, Ma DE LA S., «Notaría mayor de los privilegios rodados y Escribanía mayor de los privilegios y confirmaciones en la Cancillería real castellana» en Actas de las I Jornadas de Metodología aplicada de las Ciencias Históricas. V. Paleografía y Diplomática, Santiago de Compostela, 1975, pp. 241-254. EAD., «Las cancillerías reales castellanas. Estado actual de sus estudios», Boletín de la Sociedad Castellonense de Cultura, LVIII (1982), pp. 513-547.

3 OSTOLAZA ELIZONDO, I., «La Cancillería y otros organismos de expedición de documentos durante el reinado de Alfonso XI (1312-1350)», Anuario de Estudios Medievales, 16 (1986), pp. 147-225. EAD., «El chanciller mayor de Castilla durante el reinado de Alfonso XI (1312-1350)», Anuario de Estudios Medievales, 18 (1988), pp. 263-274. EAD., «Teoría y práctica de la función cancilleresca a través de los Ordenamientos de Cortes castellano-leoneses» en Las Cortes de Castilla y León. 1188-1988. Actas de la tercera etapa del Congreso Científico sobre la historia de las Cortes de Castilla y León, León, del 26 a 30 de septiembre de 1988, Valladolid, 1990, pp. 302-311. EAD., Administración y documentación pública castellano-leonesa durante el reinado de Sancho IV-Alfonso XI (1282-1350). Organismos, atribuciones, tipología documental, Madrid, 1991. 
dad los artículos de Pascual Martínez ${ }^{4}$ y González Crespo ${ }^{5}$ dedicados a la organización de la cancillería castellana en la primera mitad del siglo XIV, el realizado por Sanz Fuentes sobre el binomio inseparable de cancillería y cultura $^{6}$ y, de manera más general, la siempre útil monografía de García de Valdeavellano sobre la historia de las instituciones españolas ${ }^{7}$. Todos ellos nos aportan una visión general de la actividad y funciones de dicha institución y, si atendemos al reinado de Alfonso XI, observamos que se refieren, en conjunto, a las irregularidades y mala praxis de la Cancillería en tiempos de minoridad, mientras que a partir de la mayor edad (1325), a las intensas reformas que darán lugar a una modernizada oficina regia.

Nuestra pretensión con este artículo es mostrar, por medio de ejemplos concretos, cuáles fueron esas anomalías cometidas durante la tutoría de doña María y los infantes don Juan y don Pedro, abuela y tíos del rey niño. Si hay algo que caracteriza el tiempo de regencia es el desorden, la corrupción y la anarquía dimanados de la eterna pugna en el seno de la familia real por el control de la tutela ${ }^{8}$. La documentación, en los primeros compases del reinado, nos muestra a una poderosa reina doña María quien, en compañía de su hijo el infante don Pedro, ejerce la efectiva tutoría frente a la reina madre, doña Constanza de Portugal, y el infante don Juan. El necesario assensus de los diplomas - «con consejo et con otorgamiento de la reyna donna María, mi avuela, et del inffante don Pedro, mío tío, et míos tutores et guarda de los míos regnos»- así como las suscripciones de los oficiales que recogen la iussio regia - «Yo, N, la fiz escrevir por mandado del rey et de la reyna donna

4 PASCUAL MARTínEZ, L., «Notas para un estudio de la Cancillería castellana en el siglo XIV», Miscelánea Medieval Murciana, IV (1978), pp. 179-236. ID., «Notas para un estudio de la Cancillería castellana en el siglo XIV. La cancillería de Pedro I (13501454)», Miscelánea Medieval Murciana, V (1980), pp. 189-243.

5 GONZÁLEZ CRESPO, E., «Organización de la Cancillería castellana en la primera mitad del siglo XIV», En la España medieval, V (1986), pp. 447-470.

6 SANZ FUENTES, $\mathrm{M}^{\mathrm{a}} \mathrm{J}$., «Cancillería y cultura en la Castilla de los siglos XIV y XV» en G. GUALDO (ed.), Cancelleria e cultura nel Medievo Evo. Comunicazioni presentate nelle giornate di studio della Comisione [Comission internationale de Diplomatique]. Stoccarda, 29-30 agosto 1985) XVI Congreso Internazionale di Scienze Storiche, Ciudad del Vaticano, 1990, pp. 187-199.

7 GARCÍA DE VALDEAVELlANO, L., Curso de Historia de las Instituciones españolas. De los orígenes al final de la Edad Media, Madrid, 1984.

8 «Así como la ystoria a contado los fechos que pasaron en los rreynos, deve contar el estado de la tierra, en qué guisa estava en aquel tienpo; e dize que avía muchas rrazones e muchas maneras en la tierra por que las villas del rrey e los otros lugares del rreyno rresçibieron muy gran daño, por lo qual eran destruydos: ca los rricos omes e los caualleros bivían de rrobos e de tomas que fazían en la tierra, e los tutores consentíanselo por los aver cada uno de ellos en su ayuda», Gran Crónica, cap. XLIX, p. 369. 
María, su avuela, et del inffante don Pedro, su tío, et sus tutores»- hablan por sí solos 9 .

La división del reino en estas dos grandes facciones no se manifiesta únicamente en la esfera administrativa, sino también sobre el territorio donde rivalizan por dominar enclaves estratégicos para sus intereses ${ }^{10}$. El reino está dividido: Castilla, León, Galicia y Asturias son afines al bando del infante don Juan y doña María; Andalucía y Toledo, fieles al infante don Pedro. La firma de la Concordia de Palazuelos en 1314 supone un primer acuerdo en la lucha entre las partes, incorporándose a la regencia el infante don Juan, señor de Vizcaya y hermano de Sancho IV.

Estas circunstancias determinan unas prácticas cancillerescas muy similares a las existentes bajo el mandato de Fernando IV, aunque con un creciente aumento de los malos usos, abusos y desmanes de quienes ejercen los oficios. Las persistentes quejas de los concejos y representantes de las ciudades en las Cortes convocadas en Burgos (1315) y Carrión (1317) son buena muestra de ello. No ha lugar aquí volver a repetir lo que María Isabel Ostolaza tan acertadamente discernió sobre este asunto en su estudio acerca de la Cancillería ${ }^{11}$; sin embargo, sí nos gustaría apuntar el reflejo que esta mala praxis tiene en dos casos concretos: dos cartas plomadas otorgadas por Alfonso XI a la orden de Santiago.

Estos diplomas han sido escogidos por presentar ciertas particularidades que nos han hecho dudar de su originalidad. En ellos se han hallado elementos susceptibles de realizar una crítica diplomática para corroborar, de manera fehaciente, su autenticidad. Pero sobre todo, porque consideramos que son un excelente ejemplo para la investigación del quehacer cancilleresco en tiempos de minoridad.

9 AHN, OM, Uclés, carp. 243, n 21; AHN, OM, Uclés, carp. 5, vol. I, no 34; AHN, OM, Calatrava, carp. 428, $\mathrm{n}^{\circ}$ 180; AHN, OM, Uclés, carp. 338, ${ }^{\circ}$ 25; AHN, OM, Uclés, carp. 65, n⿳ 5; AHN, OM, Santa Fe de Toledo, carp. 416 bis, no 2; AHN, OM, Uclés, carp. 94, no 53 y AHN, OM, Calatrava, carp. 429, n 194. Tras la muerte de los infantes en la vega de Granada en 1319, habrá un breve periodo de tiempo en el que encontramos el consentimiento en solitario de la reina doña María (AHN, OM, San Juan, carp. 569, no 31 y AHN, OM, Uclés, carp. 338, no 25), mientras que ya, a finales de la regencia, otro del infante don Juan Manuel (AHN, OM, Uclés, carp. 338, n 25).

10 La reciente tesis doctoral elaborada por Alejandra Recuero sobre la figura de Alfonso $\mathrm{XI}$, presenta una relectura de estos primeros momentos del reinado y la lucha por la tutoría, RECUERO LISTA, A., El reinado de Alfonso XI de Castilla (1312-1350), Facultad de Filosofía y Letras, UAM, 2016 (inédita).

11 OSTOLAZA ELIZONDO, I., Administración y documentación, p. 112 y «La Cancillería y otros organismos», p. 160. Véase también GONZÁLEZ CRESPO, E., «Organización de la Cancillería», pp. 450-456. 


\section{ANÁLISIS DIPLOMÁTICO DE DOS CARTAS DE ALFONSO XI A LA ORDEN DE SANTIAGO}

Ángel Riesco, en su Vocabulario científico-técnico de Paleografía, Diplomática y ciencias afines, identifica el concepto de tradición documental con el «grado, modo, forma, materia y categoría: original, minuta, copia, falso, interpolado... en que los documentos, textos o escritos, una vez perfeccionados (concluidos) y expedidos o publicados, se nos han transmitido y llegado a nosotros ${ }^{12}$. Palabras semejantes acompañan, asimismo, a la definición dada por la Comisión Internacional de Diplomática: «sucesión o cadena de estados de un documento, entre el texto, tal y como lo ha querido su autor y su puesta en escrito por primera vez de una forma definitiva, y la que ha llegado a nosotros» ${ }^{13}$. Es decir, la traditio documental, en cuanto al método diplomático se refiere, es la forma en la que nos ha sido transmitido un diploma.

Con anterioridad, Floriano Cumbreño, a finales de los años cuarenta del pasado siglo, no satisfecho con el expresado, había acuñado el término de «ingenuidad» para referirse al «grado de relación de un documento con su origen, es decir, con el hecho documentado ${ }^{14}$. Basándose en la calificación de autenticidad jurídica, establecía una estrecha interconexión entre la veracidad del acta y la realidad que refleja con el hecho de cómo ha llegado hasta nosotros.

En lo que concierne a este trabajo, hemos considerado más adecuado seguir la metodología comúnmente aceptada de la tradición diplomática. Así, atendiendo a todo lo expuesto, discernimos entre originales y copias considerando el modo en el que nos ha sido transmitido el tenor o negocio jurídico.

Los 136 documentos que han integrado nuestro estudio y que pertenecen a la sección de Órdenes Militares del Archivo Histórico Nacional, son en su mayoría originales. Esto es, que han llegado hasta nuestros días de la misma forma en que fueron expedidos, con idénticos caracteres internos y externos y sin ningún tipo de transformación ni manipulación material ni

12 RIESCO TERRERO, A., Vocabulario científico-técnico de Paleografía, Diplomática y ciencias afines, Madrid, 2003, p. 426.

13 Textualmente: «La tradition des actes es la chaîne des états d'un document, entre le texte tel qu'il a été voulu par son auteur et mis par écrit pour la première fois d'une façon définitive et celui que nous est parvenu» en Ma M. CÁRCEL ORTÍ (ed.), Vocabulaire International de la Diplomatique, Valencia, 1997, n 24, p. 27 y Folia Caesaraugustana, I, Zaragoza, 1984, nº 21, p. 118.

14 FLORIANO CUMBREÑO, A., Curso general de Paleografía y Paleografía y Diplomática españolas, Oviedo, 1946, p. 227. 
formal ${ }^{15}$. Además, son heterógrafos, es decir, fueron realizados por mano de un tercero, escriba o notario, quien plasma por escrito la voluntad del autor en el negocio jurídico correspondiente. Sin embargo, y como dijimos anteriormente, de todos ellos hay dos que nos gustaría analizar detenidamente.

\subsection{De carta plomada y carta blanca}

El primer diploma que consideramos digno de estudio es una carta plomada otorgada en 1317 por Alfonso XI ${ }^{16}$. En él, el monarca confirma una merced de Fernando IV por la que los vasallos de la orden de Santiago quedan obligados a pagar la mitad de todos los servicios y pechos que deben dar al rey. Su apariencia externa no delata ningún tipo de sospecha, pues fue realizado en un pergamino ligeramente grueso, de gran tamaño $(612 \mathrm{~mm}$ x $630 \mathrm{~mm}+$ $70 \mathrm{~mm}$ ), forma cuadrangular y ligeramente irregular. Aunque consideramos su buena calidad y excelente estado de conservación, presenta unas manchas de humedad en el borde superior, así como algunos rotos en el borde derecho que no afectan a la lectura del texto.

Se halla escrito a renglón tendido, con amplios márgenes laterales -entre los 25 y los $35 \mathrm{~mm}-$, superior e inferior, empezando el tenor documental a $35 \mathrm{~mm}$ y finalizando a $74 \mathrm{~mm}$. La separación entre renglones oscila de 8 a $12 \mathrm{~mm}$, y a la izquierda, ocupando la altura de los tres primeros renglones, se dejó un espacio en blanco destinado a la inicial «S» de la primera palabra, «Sepan», que no se dibujó, de la misma manera que la «E» de la preposición «En» del texto insertado, algo bastante frecuente.

La lengua empleada es el romance, representada mediante trazos propios de la letra gótica de "privilegios», en tinta de tonalidad marrón; mientras que la suscripción autógrafa del personaje que recogió la iussio regia y las rúbricas, que encontramos bajo el tenor documental y en el centro y margen derecho del diploma, se llevan a cabo en ocre, aumentando la cursividad de la grafía. En la plica se observan tres orificios de forma romboidal, conservando, anudados, los vínculos en hilos de seda rojo y blanco, de los que pendería en aposición triple el sello de plomo, que no se conserva.

En cuanto a sus características internas, este instrumento público presenta una estructura diplomática singular e híbrida, situándose a caballo entre el más solemne de los documentos cancillerescos y las cartas plomadas de inicio notificativo. Así, principia por la conocida notificatio universal en la que

15 Del total de los 136 diplomas conservados analizados, 64 se corresponden con el calificativo de auténtico u original, lo que supone un $47 \%$ del conjunto documental; el restante $53 \%$ se inscribe en el epígrafe de copias.

16 AHN, OM, Uclés, carp. 5, vol. I, nº 37. 
se incluye la autocalificación de "privilegio ${ }^{17}$ unida, por medio del adverbio «cómmo» y el pronombre personal «nos», a la intitulatio regia completa. Se compone de tratamiento, nombre propio, fórmula de derecho divino y la larga enumeración de estados pertenecientes a la Corona, situando a Toledo inmediatamente después de Castilla ${ }^{18}$.

Le sigue un expositivo amplio cuyo primer elemento es la «vista» por parte de Alfonso XI de un privilegio rodado de su progenitor, Fernando IV, indicándose las características fundamentales de la materia y tipo de sello empleado en su validación. Se inserta el texto in extenso, incluyéndose las columnas de confirmantes y la suscripción del amanuense, previo anuncio mediante la expresión «fecho en esta guisa». Tras él, se hace relación de la petitio que el maestre de Santiago, don Garci Fernández, presenta para que les sea confirmado a él y a su Orden el privilegio mencionado. El monarca, «por fazer bien et merçed»y «por muchos serviçios que la dicha Orden faze a los reyes onde nos venimos et faze agora a nos», accede al ruego con el consejo y consentimiento de los tutores, pues recordemos que se expidió en época de minoría.

El dispositivo contiene, por tanto, la concesión de la merced explicitada a partir de los verbos «confirmar», «otorgar» y «mandar» en primera persona del plural. Las cláusulas que refuerzan el acto jurídico son diversas. Comienza con la prohibitiva que sanciona, bajo la amenaza de incurrir en la ira regis, con una multa pecuniaria y la restitución del doble del daño causado a los lesionados, finalizando el texto con el anuncio de validación, no sin antes incluir una fórmula corroborativa.

«Et deffendemos firmemiente que ninguno non sea osado de yr nin de passar contra él para lo menguar nin para lo quebrantar en ninguna manera, si non qualquier o qualesquier que lo fiziessen avríe nuestra yra et pecharnosya en coto la pena de los diez mill maravedís sobredichos, et al maestre et a la Orden sobredicha, o a quien su boz toviesse, todo el danno et el menoscabo que por ende reçibiesse doblado. Et porque esto sea firme et estable, mandamos seellar este privillegio con nuestro seello de plomo».

Hasta aquí todo resulta similar a lo observado para las cartas plomadas, excepción hecha de la autocalificación como «privilegio»; sin embargo, el escatocolo ofrece determinadas particularidades que son propias de los rodados. A saber, la data se abre con el participio «Fecho»y, de nuevo, la autocalificación diplomática de «privilegio», indicando el lugar de expedi-

17 En lugar de la genérica de «carta», la más adecuada desde el punto de vista diplomático y, por otra parte, la más usual en estos casos.

18 BENITO RUANO, E., La prelación ciudadana. Las disputas por la precedencia entre las ciudades de la Corona de Castilla, s.l., 1972. 
ción y la información crónica: el día del mes en estilo directo y el año por la Era Hispánica. A continuación, una subscriptio regia encabezada por la conjunción copulativa «et», el pronombre de primera persona en plural, el nombre del soberano y la enumeración de los reinos y señoríos precedidos del gerundio «regnante». Entre los dominios se incluyen, además, Baeza y Badajoz, nombres que, como se puede comprobar, no se hallan en la intitulación del comienzo pero cuya inserción es habitual. Finalmente, la expresión de otorgamiento del privilegio ${ }^{19}$.

En ausencia de columnas de confirmantes y de la rueda, dos de los elementos que singularizan el diploma más solemne de la Cancillería real, concluye el tenor documental con las suscripciones de Juan Rodríguez de Seseña, camarero mayor del infante don Pedro y «chançeller del rey de las

TABLA 1. Estructura documental del documento AHN, OM, Uclés, carp. 5, vol. I, no 37

\begin{tabular}{|c|c|}
\hline \multicolumn{2}{|c|}{ ESTRUCTURA DOCUMENTAL DOC. N ${ }^{\circ} 1$} \\
\hline NOTIFICACIÓN & «Sepan quantos este privilegio vieren...» \\
\hline INTITULACIÓN & $1^{a}$ pers. del plural \\
\hline EXPOSICIÓN & $\begin{array}{c}\text { Vista } \\
\text { Inserción in extenso } \\
\text { Petitio } \\
\text { Motivación y accesio con el consejo y otorgamiento de } \\
\text { los tutores }\end{array}$ \\
\hline DISPOSICIÓN & $\begin{array}{c}\text { «...tenémoslo por bien, otorgamos este privillegio et } \\
\text { conffirmámoslo et mandamos...» }\end{array}$ \\
\hline Cláusulas Finales & $\begin{array}{c}\text { Prohibitiva } \\
\text { Penal (ira regia, pecuniaria y restitutio in duplum) } \\
\text { Corroborativa } \\
\text { Anuncio de validación }\end{array}$ \\
\hline DATA & «Fecho el privilegio...» \\
\hline VALIDACIÓN & $\begin{array}{c}\text { Suscripción real } \\
\text { Suscripción de quien transmite la iussio regia y del } \\
\text { oficial que la hace escribir } \\
\text { Sello de plomo }\end{array}$ \\
\hline
\end{tabular}

19 «Et nos el sobredicho rey don Alffonsso, regnante en Castiella, en Toledo et en León, en Gallizia, en Sevilla, en Córdova, en Murçia, en Jahén, en Baeça, en Badajoz, en el Algarbe et en Molina, otorgamos este privillegio et conffirmámoslo». 
sus cartas blancas que don Pedro trae», en calidad de oficial que recoge la iussio regia, y de Martín Domínguez, que lo hizo escribir, indicando además el año del reinado - «en el anno quinto que el rey sobredicho regnó»-.

Esta validación tan peculiar ha sido un verdadero reto para nosotros, pues no conocíamos ningún ejemplo semejante. En primer lugar, pocos son los datos que acerca del término «carta blanca» hemos encontrado en los vocabularios, diccionarios y trabajos de nuestras disciplinas y otras afines como pudiera ser la Historia del Derecho ${ }^{20}$. Ángel Riesco Terrero nada menciona sobre esta singular carta ${ }^{21}$; María Milagros Cárcel Ortí y, por extensión, Folia Cesaraugustana no recogen ningún tipo de información al respecto ${ }^{22}$. Las únicas referencias de las que disponemos son las de Isabel Ostolaza Elizondo, quien señala que estos documentos «podrían considerarse como cartas falsas, pues su expedición no se sometía a las normas de cancillería, aunque estuvieran validadas por el sello real. Por eso su cumplimiento no obligaba a las autoridades a las que iban dirigidas» ${ }^{23}$, y la alusión a unas "cédulas albas» que María Luisa Cabanes constriñe a aquellas cédulas que carecen de dirección $^{24}$. Sin embargo, tanto una como otra definición no se ajustan a lo que en la documentación contemporánea tildan de «carta blanca». En el ámbito cancilleresco, por ejemplo, observamos que es habitual la aparición de este tipo de documento. Ya en la Ordenanza de Valladolid de 1312 se establece que:

«... los que estudieren a la tabla de los míos sellos que non den ninguna carta blanca sellada con el mío seello de los que yo mandar dar, sin so alvalá de aquel a quien las diere por mío mandado. E los que desta guisa dieren, que demande cuenta al que las levó de las cartas quel dieren a el que sea tenido de ge la dar. E las cartas que fincaren en él, que las torne al chançeller, e él que las rompa allí a la tabla ante todos» ${ }^{25}$.

En el contexto de este documento, minoría de edad del rey niño, las cartas blancas debían expedirse con mucha facilidad. En nuestra búsqueda por encontrar otros testimonios similares, hemos hallado una interesante nómi-

20 Únicamente en el Diccionario de términos jurídicos de Villa-Real Molina y Arco Torres se recoge la acepción de «carta blanca» como «La que se da a una autoridad para que obre discrecionalmente (DRAE)», VILLA-REAL MOLINA, R. y DEL ARCO TORRES, M. A., Diccionario de términos jurídicos, Granada, 2006, p. 72.

21 RIESCO TERRERO, A., Vocabulario, Madrid, 2003.

22 CÁRCEL ORTÍ, Mª M. (ed.), Vocabulaire, Valencia, 1997 y Folia Caesaraugustana, Zaragoza, 1984.

23 OSTOLAZA ELIZONDO, I., «La Cancillería y otros organismos», p. 184.

24 CABANES CATALÁ, Ma L., «La monarquía hispánica de los Reyes Católicos y sus usos cancillerescos» en Isabel I y la imprenta. Consecuencias materiales en el mundo cultural de esta revolución tecnológica, Madrid, 2004, pp. 21-22.

$25 \mathrm{RAH}$, Cortes de los antiguos reinos de León y de Castilla, I, Madrid, p. 206. 
na de ejemplos en el Corpus Diacrónico del Español (CORDE). Descartando todos aquellos que se refieren al juego de naipes, nos restan los casos que se ajustan a los usos y prácticas cancillerescos que estamos analizando. Los seis primeros textos se extraen de la Concordia de Palazuelos (1314) y, de manera inmediata, responden perfectamente a las incógnitas que nos plantea este tipo tan peculiar.

«Otrossí, nos, la reyna donna María et el infante don Johán et el infante don Pedro touiemos por bien et ordenamos que la Chancelería del dicho rey don Alfonso que esté siempre doquier que el rey fuere, et los seellos que los tenga el chanceller aquel que nos todos tres los tutores acordaremos. Et la archa do estudieren los seellos que ay tres llaues et que tenga yo, la reyna donna María, la una, et yo, el infante don Johán, la otra et yo, el infante don Pedro, la otra. Et quando acaesciere que nos, el infante don Johán, o el infante don Pedro nos oviéremos a partir del rey pora yr a otras partes, que cada uno de nos tomemos cartas blancas seelladas con el seello del rey aquellas que oviéremos mester pora levar connusco et que las tomemos con recaudo. Et las cartas blancas que cada uno de nos levare que sean puestas en dos archas: la una que lieue yo, el infante don Johán, et la otra que lieve yo el infante don Pedro.

Et cada una de estas archas aya dos llaves: la una pora nos, la reyna donna María et el infante don Pedro, et la otra pora mí, el infante don Johán. Et que la archa que yo, el infante don Johán, levare con estas cartas blancas que la lieve un mi omne et que vaya y conmigo un omne de vos, la reyna donna María et del infante don Pedro con la vuestra llave.

Et quando algunas daquellas cartas blancas oviese de escrevir que sean libradas del omne de vos, la reyna donna María et el infante don Pedro, et del omne de mí, el infante don Johán, et que en otra manera non se escriva. Et que en esta misma manera se faga en la archa et en las cartas blancas que yo, el infante don Pedro, levare commo dicho es.

Et quando amos o qualquier de nos, el infante don Johán et el infante don Pedro, llegáremos do el rey fuere que en cuanto y estudiéremos que non usemos de las cartas blancas que leváremos et que demos recaudo de las que mandamos dar cada uno de nos» ${ }^{26}$.

Del texto se deduce que, los tutores del Onceno, para una mayor eficiencia y practicidad en atención de los asuntos de gobierno, disponen de un número indeterminado de cartas blancas, selladas con el sello real pero aún por escribir, las cuales estarían convenientemente custodiadas en dos arcas bajo llave. Estos diplomas, que podemos definir como extracancillerescos, sólo se emitirían cuando los infantes don Pedro y don Juan se vieran en la

26 GIMÉNEZ SOLER, A., Don Juan Manuel: biografía y estudio crítico, Zaragoza, 1932, doc. CCCIII, p. 452 y capítulo XI de la Crónica. 
necesidad de «partir del rey pora yr a otras partes», pues en el momento en el que volviesen junto al monarca, no podían usar de ellas y habían de justificar todas aquellas cartas blancas que habían expedido. Por lo tanto,

«...asistimos durante los años de su menor edad a diferentes etapas en las que el protagonismo político de los diferentes tutores fue acompañado de una producción documental cancilleresca expedida desde los distintos puntos de actividad política en los que se encontraban, impidiendo que aquellos documentos encabezados la mayor parte de las veces por el nombre del rey nos permitan conocer con precisión la presencia del monarca en aquellas localidades ${ }^{27}$.

Ahondando un poco más, comprobamos que la concordia fue ratificada en las Cortes de Burgos de $1315^{28}$, volviendo a insistir en los mismos términos y del mismo modo, y durante el periodo que abarca la segunda tutoría, encontramos datos fidedignos que indican la expedición y uso continuado de este singular tipo documental. Verbigracia, en el capítulo XLI de la Crónica, una vez Alfonso XI cumple la mayoría de edad, se narra que los infantes don Felipe y don Juan «dieron al rey las cartas blancas que tenían selladas con el sello que el rey tenía, et con que ellos usaban de las tutorías», eventualidad que se constata en una carta del Onceno dirigida al concejo de Murcia comunicándole que ha tomado en su mano el gobierno, por lo que en adelante debe abstenerse de obedecer las órdenes que «por las mis cartas blancas que trahe el infante don Felipe et don Johán, fijo del infante don Manuel, nin por ninguna carta de las suyas, nin usedes con ellos, nin con los oficiales que ellos posieron por sy por rasón de la tutoría» ${ }^{29}$.

La mayoría de edad conllevó un mayor control de la Cancillería, sentando las bases de un exhaustivo proceso de regularización de la expedición de documentos públicos en la administración castellana, como veremos más adelante, pero este peculiar tipo diplomático no desaparecerá. Las referencias a las cartas blancas continúan en las reuniones de Cortes celebradas en Valladolid (1325) y Madrid (1329 y 1339) (10 $^{30}$ en unos términos, además, que

27 CAÑAS GÁlVEZ, F. DE P., Itinerario de Alfonso XI de Castilla. Espacio, poder y corte (1325-1350), Madrid, 2014, pp. 20-21.

28 «Otrossí que non ande en la tierra carta de creençia nin blanca del rey nin nuestra, nin demos alvalá nos los tutores nin ninguno de nos con nuestros nombres nin carta nuestra para fazer ninguna cosa en el regno salvo de complimiento de las del rey. Et si alguno trajere tal carta o tal alvalá, que los concejos nin los offiçiales que non usen dellos, salvo las cartas blancas del rey que nos los tutores traxiermos como fue ordenado en Palaçuelos», RAH, Cortes, I, Madrid, 1861, p. 276.

29 1325, agosto, 15. Valladolid. AMM, C.R. 1314-1344, ff. 14v-15r. Editada en GIMÉNEZ SOLER, A., Don Juan Manuel, doc. CCCLXXXVI, pp. 509-510.

30 «Otrossí a lo que me pedieron por merçed que non ande en la mi tierra carta 
nos revelan la cotidianidad con la que eran empleadas y la necesidad de su erradicación, de modo que, las reiteradas advertencias para que su emisión se viera sometida a las pertinentes comprobaciones de la oficina encargada de la elaboración del documento real, son más que elocuentes ${ }^{31}$.

Además, esta manifestación diplomática no es restrictiva del ámbito regio y los ejemplos se suceden también en el señorial. El infante don Juan Manuel, por ejemplo, solía valerse de ellas a menudo, tal y como se puede comprobar en la colección diplomática que acompaña a la biografía escrita por Andrés Giménez ${ }^{32}$. Mostramos aquí un pequeño extracto de un albalá de Fernán Sánchez de Valladolid quien, como canciller del rey, da cuenta del recibo de diversas cartas de este tipo que fueron confiscadas antes de llegar a sus destinatarios:

«Sepan quantos este alvalá vieren cómo yo, Fernán Sánchez de Valladolit, chanceller del rey, otorgo e conosco que rescebí para el rey de vos, Pero López de Ayala, quatro cartas blancas seelladas con el seello de don Johán, fijo del infante don Manuel, de çera colgado: las dos de pergamino e las dos de papel. Otrossy recebí ocho cartas de papel blancas seelladas con el seello del dicho don Johán en las espaldas. Et recebí más de vos el dicho Pero Lopes de Ayala para el dicho sennor Rey, çinco cartas del dicho don Johán escriptas en

blanca que non sea escripta e leyda e librada en la mi Chancellería»; "Otrossí a lo que me pidieron por merçet que non salga de la mi Chançellería carta blanca que non sea escripta e leyda e librada en la mi Chançellería», Cortes, II, pp. 373, 414, 456 y 457.

31 Las cartas blancas son un verdadero quebradero de cabeza para los reyes castellanos venideros pues encontramos múltiples ejemplos en la legislación desde la Baja Edad Media y en la Edad Moderna. De entre ellos, nos han parecido significativas las palabras de Juan II en las que afirma «a mi es hecha relación que vos o algunos de vos tenedes en vuestro poder algunas mis cartas y alvalaes firmadas de mi nombre en blanco, las quales yo me moví a librar e fiar de vos e de otros algunos por algunas cosas que por entonces entendía ser cumplideras a mi servicio, ansí por causa de las guerras pasadas que yo he habido con los moros e con otros reynos y personas, como por causa de los movimientos pasados que han sydo e acaecido en mis reynos; las quales cartas ansí firmadas en blanco, han detenido y detienen en sí aquellos a quien fueron dadas y de quien fueron fiadas e otros algunos, e no ha dado ni tomado, de lo qual en el tiempo advenidero a mí y a mi patrimonio e fisco, y a la Corona real de mis reynos se podrían recrescer gran deservicio y daño y perjuicio, e aún a otros algunos... porque las tales cartas blancas podrían ser llanas y henchidas por algunas personas, e puestas y escritas en ellas muchas gracias y mercedes y donaciones y otras cosas ansí de patrimonio e fisco, como de otras personas y en otra qualquier manera... en gran perjuicio mío e de otro tercero, yo no habiendo hecho ni mandado las tales cosas», PÉREZ DE GUZMÁN, G., Crónica del señor rey don Juan, segundo de este nombre en Castilla y en León, Valencia, 1779, pp. 445-447. Asimismo en la Novísima Recopilación, encontramos referencias a las «cartas blancas», libro IV, 12, 3.

32 GIMÉNEZ SOLER, A., Don Juan Manuel, pp. 551-558. 
papel e seelladas con su seello en las espaldas, de las quales yvan las dos dellas a Pero Martínez Calvillo e la una al concejo de Lorca e la otra a Yennego Ximénez de Lorca, e la otra a Alfonso Ferrández, comendador de Aledo.... ${ }^{33}$.

Observamos cómo discierne de manera clara entre cartas blancas y el resto de diplomas. Elocuentes son también las palabras del propio infante don Juan Manuel. Movido por la búsqueda de alianzas con el concejo de Lorca y con el rey de Granada para hacer frente al monarca castellano, sobre todo tras el rechazo de su hija como reina consorte y el definitivo matrimonio de Alfonso XI con María de Portugal, manda redactar un total de doce cartas blancas a su escribano. El documento en cuestión dice así:

«...et porque tan complidamente non se podría acá escrevir la carta de lo que se debe façer en esto, enbío vos la blanca a vos, façetla escribir en aquella guisa que cumple. Et assí para esto commo para ell otro pleito que me enbiastes decir de los moros, enbío vos dotçe cartas blancas con Ruy Pérez, mío escrivano, las quatro del seello menor ${ }^{34}$.

Desafortunadamente para don Juan Manuel, los mensajeros fueron interceptados y con ellos los documentos, mandando Alfonso XI a Pedro López de Ayala que «dedes todas esas cartas que y tomastes que embiava don Johán, también las escriptas como las blancas et todas las otras escripturas que con ellas tomastes, al cardenal don Pedro a qui yo embío desir que me las traya ${ }^{35}$.

Quedémonos con esta última expresión. Como ya hemos apuntado, en ausencia de una definición en los diccionarios y vocabularios especializados en Ciencias y Técnicas Historiográficas, así como en los referidos a Historia del Derecho, y teniendo en cuenta las noticias que hemos extraído a partir de la documentación contemporánea al periodo cronológico tratado, entendemos que «carta blanca» es cualquier instrumento público validado con el sello correspondiente -plomo, cera, mayor, menor-, pero cuyo tenor documental no ha sido aún puesto por escrito. Mediante esta fórmula, la persona que tuviese bajo su custodia dichas cartas poseía plenas facultades para expedir tal o cual documento, al gozar de la absoluta y plena confianza del emisor. Quizás la mayoría de las veces éstas sirviesen más a sus propios intereses que a los del monarca o señor, de ahí las intensas advertencias y reiteraciones de Alfonso XI en Cortes tras hacerse cargo del gobierno para que obligatoriamente pasasen por los comunes cauces de la Cancillería. No contemplamos, a priori, la falsedad de estos diplomas que Isabel Ostolaza

33 Ibid., doc. D, p. 591.

34 Ibid., doc. CCCCL, p. 552.

35 Ibid., doc. CCCCLII, p. 559. 
les atribuye, pues atendiendo al análisis de nuestro ejemplar y a las informaciones obtenidas, presentan todas las formalidades legales y jurídicas de la Cancillería, y, aún a pesar de que su conscriptio se haya visto alterada, esta manifestación documental comporta una relación de lealtad y confianza entre la persona que entrega la «carta blanca» y la que la recibe, declarando de antemano la conformidad de aquél con lo que contenga el diploma una vez se proceda a su escrituración. Corrobora en cierta manera esta hipótesis el hecho de que «carta blanca», a pesar de no hallarse como categoría diplomática en ningún vocabulario específico de la materia, ha perdurado en el lenguaje común mediante la expresión «dar carta blanca a alguien». Esto es, «darle plena y absoluta facultad para que haga y execute lo que quisiere, o le pareciere conveniente tocante a alguna materia, dependencia, o tratado», como bien aclara el Diccionario de Autoridades.

A tenor de lo dicho hasta ahora, el análisis pormenorizado de sus caracteres internos y externos nos ha dado muestras de que este documento reviste todas las garantías jurídicas. Sus fórmulas y su estructura diplomáticas son ciertamente particulares, pero quizás, en la emisión extracancilleresca de este testimonio podamos entrever los primeros balbuceos de la carta de confirmación y privilegio, cuya presencia primigenia se atestigua ya en el reinado de Pedro I y cuya consolidación tuvo lugar ya entre los siglos XIV y $\mathrm{XV}$, durante los gobiernos de Juan I, Enrique III, Juan II y Enrique IV, siendo su nacimiento del todo incierto. Es una primera hipótesis pues sólo el estudio pormenorizado de series documentales bajomedievales, tanto éditas como inéditas, permitiría clarificar el recorrido desde las cartas plomadas en su evolución hacia los nuevos tipos documentales semisolemnes, destinados, sin duda, a satisfacer las crecientes necesidades de la administración central en sus pasos hacia la modernidad.

\subsection{De originales y confirmaciones}

El segundo documento se corresponde también con una carta plomada de Alfonso XI, confirmatoria a su vez de otra del mismo monarca por la que renueva al maestre y orden de Santiago los privilegios y exenciones de pechos otorgados por su progenitor, Fernando IV, y su abuelo, Sancho IV ${ }^{36}$.

El material empleado es el pergamino, de textura gruesa, buena calidad y tamaño rectangular $(428 \mathrm{~mm}$ x $380 \mathrm{~mm}+67 \mathrm{~mm})$. El texto, en romance y tinta ocre oscura, se dispone a renglón tendido dejando amplios márgenes superior, inferior e izquierdo, que oscilan entre los 30 y los $32 \mathrm{~mm}$, no así el

36 AHN, OM, Uclés, carp. 2, vol. I, no 22. 
derecho, que se sitúa en los $5 \mathrm{~mm}$. Los espacios interlineares, por su parte, son de $3 \mathrm{~mm}$. El estado de conservación es ciertamente regular, ya que se pueden observar pequeñas manchas de humedad y algunos pliegues, especialmente en los márgenes, que han provocado que se rasgue el documento. También comprobamos la existencia de varios agujeros en la zona central y junto a una de las rúbricas, dificultando, en determinados puntos, la lectura del texto. La plica presenta tres orificios romboidales, permitiendo la aposición triple del sello plúmbeo, hoy perdido, así como los vínculos que lo mantendrían unido al soporte.

Desde el punto de vista gráfico, el pergamino recibió una escritura gótica minúscula documental tipificada o gótica documental fracturada formada, tradicionalmente llamada «letra de privilegios», propia de este tipo documental en el arco cronológico en el que nos movemos; aumentando en rapidez en la suscripción autógrafa del escribano que realizó el instrumento, Martín Domínguez, oficial de la Cancillería que ya conocemos gracias a otros instrumentos elaborados por él mismo ${ }^{37}$ y cuya ejecución de las formas gráficas coincide plenamente en todos los casos.

Si atendemos a la estructura documental, ha sido por medio de su análisis que hemos tenido que poner en cuarentena este documento.

Como comentábamos al inicio, nos encontramos ante una carta plomada. El tenor documental se inicia con la fórmula de notificación y dirección «Sepan quantos esta carta vieren». Mediante el adverbio de modo «cómmo» ésta queda unida a la intitulación regia completa, aunque en solitario y sin el acompañamiento de reina e infante, que se encabeza por el pronombre personal «yo». La intitulatio se rodea de los elementos ya descritos en el caso anterior: al tratamiento «don», le siguen el nombre del monarca, la declaración de derecho divino, el título real y la relación de los estados pertenecientes a la Corona.

Al estar ante una carta ratificatoria de otra, la exposición de motivos queda claramente definida por la habitual fórmula de «vista», en la que el rey deja constancia de haber examinado materialmente el documento del que se pide confirmación. En ella se menciona la descripción de determinadas características externas, como la materia escritoria, en este caso, papel, finalizando con la expresión «fecha en esta guisa». Sin dilación, se transcribe el instrumento objeto de confirmación, pero en esta ocasión no por completo, pues comienza directamente con el expositivo «Porque yo e la reyna donna María...», omitiendo cualquier tipo de protocolo.

37 AHN, OM, Uclés, carp. 2, vol. I, no 21; AHN, OM, Uclés, carp. 5, vol. I, nºs 36, 37 y 38; AHN, Sigilografía, c. 18, nº 3. 
Una vez reproducida la carta, se sucede el ruego del beneficiario al monarca. Siempre iniciado con la partícula «Et agora», le acompaña el nombre del interesado (García Pérez, prior de Uclés) y la petitio, la parte más importante del texto, pues en ésta se encuentra el origen del negocio jurídico que da lugar a la actio documental. El asentimiento del rey, que gobierna en minoridad, viene acompañado del assensus y otorgatio de aquellos que en realidad ejercen el poder, sus tutores.

El dipositivo reúne, mediante verbos de corroboración y concesión - «otórgogela e conffírgela»-, la expresa voluntad regia de que la concesión se haga efectiva, dejando para el final el inyuntivo «mando», en aras de transmitir el deseo de que la merced confirmada posea la misma vigencia y valor en su reinado que en tiempos pasados.

La última parte del texto la constituyen las cláusulas finales cuyo propósito no es otro que el de garantizar la ejecución del acto documentado. En primer lugar, se establece un precepto de carácter inyuntivo dirigido a las autoridades, civiles o eclesiásticas, para que se cumpla lo así dispuesto. Esta queda reforzada con otro ya de carácter general en el que se conmina a no contravenir u obstaculizar lo establecido por el monarca pues, en el caso de que así sea, se establece una multa pecuniaria fija y al prior y canónigos

TABLA 2. Estructura documental del documento AHN, OM, Uclés, carp. 2, vol. I, n 22

\begin{tabular}{|c|c|}
\hline \multicolumn{2}{|r|}{ ESTRUCTURA DOCUMENTAL DOC. $\mathrm{N}^{\circ} 2$} \\
\hline NOTIFICACIÓN & «Sepan quantos essta carta vieren...» \\
\hline INTITULACIÓN & $1^{\mathrm{a}}$ pers. del singular \\
\hline EXPOSICIÓN & $\begin{array}{c}\text { Vista } \\
\text { Inserción in extenso } \\
\text { Petitio } \\
\text { Accesio con el consejo y otorgamiento de los tutores }\end{array}$ \\
\hline DISPOSICIÓN & «...otorgógela e conffírgela e mando...» \\
\hline CLÁUSULAS FINALES & $\begin{array}{c}\text { Conminatoria + sanción } \\
\text { Preceptiva } \\
\text { Prohibitiva } \\
\text { Penal (pecuniaria y restitutio in duplum) } \\
\text { Anuncio de validación }\end{array}$ \\
\hline DATA & Tópica + Crónica \\
\hline VALIDACIÓN & $\begin{array}{l}\text { Suscripción cancilleresca } \\
\text { Sello de plomo pendiente }\end{array}$ \\
\hline
\end{tabular}


de Uclés, el doble del daño causado. También se incluye el anuncio de validación, en el que se emplea la autocalificación de «carta» y la materia del sigillum: plomo.

El fin del tenor documental lo constituye el escatocolo, que está compuesto por dos elementos indispensables: la datación y la validación. La data, con referencia al lugar del otorgamiento, así como al tiempo en que fue emitida, se enuncia con el participio «Dada», el topónimo precedido de la preposición «en» y el componente cronológico: día y mes en estilo directo y el año por la Era Hispánica expresado en letra. La validación, por su parte, comprende las suscripciones y rúbricas de aquellos que han intervenido en la puesta por escrito del negocio jurídico y que avalan el acto documentado, y el sello de plomo pendiente, hoy perdido.

La estructura diplomática del documento inserto podría identificarse bien con una carta abierta, bien con una real provisión, hipótesis que no podemos constatar al no haberse copiado el protocolo inicial y no tener ante nosotros el original. El resto del diploma posee todos los elementos estructurales característicos de estos tipos documentales.

El expositivo da cuenta de que el rey don Alfonso y su abuela, la reina doña María, así como los infantes don Juan y don Pedro, han visto una carta de Fernando IV. En esta fórmula de «vista» no se menciona en ningún caso la materia o el modo de validación, sin embargo sí se recoge el nombre del monarca de quien emanó, su parentesco y una expresión piadosa, finalizando con la expresión «fecha en esta guisa». Tras la inserción in extenso de los diplomas de Fernando IV, que incluye a su vez otra de Sancho IV, se describe la petición realizada por parte de fray Pay Rodríguez, prior de Uclés, para que el Onceno confirme los privilegios y la exención de pechos de que la orden de Santiago ha disfrutado hasta el momento.

Así es, hallamos la definitiva accesio del monarca, con su oportuno dispositivo mediante la fórmula "conffírmol essta carta e mando que vala e le sea guardada en todo bien e conplidamente». Concluye con las cláusulas finales de carácter penal, la prohibitiva y de anuncio de validación, además de la data -tanto tópica como crónica-, y la suscripción del escribano y rúbricas de los oficiales de la Cancillería regia, que también se transcriben. 
TABLA 3. Estructura documental del documento inserto en AHN, OM, Uclés, carp. 2, vol. I, nº 22

\begin{tabular}{|c|c|}
\hline \multicolumn{2}{|c|}{ ESTRUCTURA DOCUMENTAL DEL INSERTO EN DOC. N ${ }^{\circ} 2$} \\
\hline NOTIFICACIÓN & - \\
\hline INTITULACIÓN & - \\
\hline EXPOSICIÓN & $\begin{array}{c}\text { Vista } \\
\text { Inserción in extenso } \\
\text { Petitio }\end{array}$ \\
\hline DISPOSICIÓN & Accesio con el consejo y otorgamiento de los tutores \\
\hline CLÁUSULAS FINALES & «...conffírmol esta carta e mando...» \\
\hline DATA & $\begin{array}{c}\text { Prohibitiva } \\
\text { Conminatoria } \\
\text { Anuncio de validación }\end{array}$ \\
\hline VALIDACIÓN & Tópica + Crónica \\
\hline
\end{tabular}

Si observamos el cuadro de tradición documental ${ }^{38}$, advertimos que, a pesar de que no contamos con el original del documento inserto, sí que existe una segunda copia incluida en un privilegio rodado de Juan II expedido en 1430. El estado de conservación es bastante regular, pues la tinta se encuentra desvaída en los inicios de la carta; sin embargo ello no ha sido impedimento para poder realizar la lectura del texto. El diploma principia con la notificación, seguida de la intitulación y de la fórmula de «vista», en la que el rey afirma haber visto un privilegio de Alfonso XI, «escrito en pergamino de cuero et sellado con su sello de plomo pendiente en filos de seda». Es decir, el testimonio que tuvo ante él es la misma carta que nosotros hemos puesto en cuarentena, la cual, efectivamente estaría validada con el sigillum plúmbeo. Este monarca, un siglo más tarde, confirma este documento del Onceno y realiza la inserción in extenso del mismo, que a su vez recoge otro del año 1315, iniciada directamente con el expositivo, y las dos de sus predecesores.

Descartamos, de este modo, la posibilidad de que la carta del Justiciero sea un falso realizado fuera de la Cancillería y nos reafirmamos en la veracidad del contenido y tenor documenal, que volvió a confirmarse sin titubeos en tiempos de Juan II. La hipótesis que barajamos es la del error humano que, además, fue doble. En primer lugar, el lapsus pennae del amanuense

38 Remitimos al anexo que acompaña a este estudio. 
al iniciar el inserto directamente por la expositio, sin recoger los elementos propios de cualquier documento público expedido en tiempo y forma. Dadas las circunstancias, cabe preguntarse si el original en papel estaba deteriorado y esto hacía ilegible los primeros renglones, pero si esto fue así ¿por qué no se mencionó tal eventualidad? En segundo lugar, se detecta un fallo en el proceso de génesis documental, concretamente en la recognitio. No se comprobó de manera exhaustiva si la redacción del documento era la correcta a partir del mundum, siendo validado con el sello de plomo y las suscripciones de los oficiales a pesar de los equívocos ya mencionados.

\section{CONCLUSIONES}

Estas anomalías apreciadas en los diplomas que acabamos de mencionar, sin duda, deben ser puestas en relación con el contexto al que se circunscriben. Atendiendo a la fecha en que fueron emitidos los documentos (1317 y 1318), hacía poco tiempo que las Cortes se habían congregado en Medina del Campo y en el actual municipio palentino de Carrión de los Condes. En ellas se expresaron de forma clara las corruptelas y mala praxis de quienes gestionaban la Cancillería real, sobrevenidas por la inestabilidad propia de la minoridad regia. Creemos conveniente recoger una de sus disposiciones, pues en ella se describe este hecho puntual.

«Otrossy a lo que nos pedieron que en fecho de la Chançellaría, que nos que toviéssemos por bien de poner y mayor recabdo porque se non fizieren tan desaguisadamientre commo se feziera fasta aquí... Et aquellos que estas llaves tovieren, que non seellen ninguna carta sin vistas sigunt que fuere ordenado, et si la seellaren sinnon commo dicho es, que los maten por ello» ${ }^{39}$.

En el fondo de toda cuestión se hallan los continuos enfrentamientos entre la reina doña María y los infantes don Pedro y don Juan por recabar apoyos en los diversos territorios de la corona castellano-leonesa y, por supuesto, peninsulares, en aras de una tutoría sostenida. En este incesante ir y venir de alianzas y discordias, la Cancillería queda relegada a un segundo plano, queda totalmente descuidada, cometiéndose irregularidades como las que hemos visto y como las que se denuncian habitualmente en las reuniones de Cortes. Ciertamente, hemos de tener en cuenta la enorme conflictividad imperante a todos los niveles en el periodo de 1312 a 1325, año este último en el que el Onceno accede a la mayoría de edad y, con mano firme, se hace cargo del reino; pero, aún con todo, consideramos que el reflejo en la documentación analizada de esa inestabilidad es mínima pues, de manera general,

39 RAH, Cortes, I, pp. 301-302. 
podemos decir que los pergaminos originales estudiados cumplen con todos los requisitos y elementos probatorios de veracidad, salvo las excepciones señaladas en el presente trabajo.

\section{ANEXO DOCUMENTAL}

1317, agosto, 10. Córdoba.

Alfonso XI confirma una merced de Fernando IV por la que los vasallos de la orden de Santiago quedan obligados a pagar la mitad de todos los servicios y pechos que deben dar al rey.

A. AHN, OM, Uclés, carp. 5, vol. I, no 37 . Pergamino cuadrangular de gran tamaño $-612 \mathrm{~mm}$ x $630 \mathrm{~mm}+70 \mathrm{~mm}-$ y ligeramente irregular. Margen superior e izquierdo de $35 \mathrm{~mm}$, derecho de entre 35 y 25 $\mathrm{mm}$ e inferior de $74 \mathrm{~mm}$. La separación entre renglones es de $8 \mathrm{y}$ $12 \mathrm{~mm}$. A la izquierda y ocupando la altura de los tres primeros renglones, se dejó un espacio en blanco destinado a la inicial «S» de la primera palabra, «Sepan», que no se dibujó. La materia es gruesa, de buena calidad y excelente estado de conservación, aunque con unas manchas de humedad en el borde superior, así como algunos rotos en el borde derecho que no afectan a la lectura del texto. En la plica se conservan anudados los vínculos en hilos de seda rojo y blanco de los que pendía en aposición triple el sello que no se conserva. Tinta color marrón y letra gótica minúscula documental tipificada. En la suscripción autógrafa del personaje que recogió la iussio regia, la escritura aumenta en cursividad.

Notas archivísticas al dorso: en la mitad inferior, centrado, con tinta oscura y bastardilla redonda del siglo XVIII: «Era 1355. Año 1317». A la derecha del año, se añadió en lápiz azul: «agosto, 10». En humanística redonda «Pedidos./ Caxón 5,/ volumen 1,/ número 37» y debajo, en grafía gótica y tinta clara, «Pedidos». Cerca del margen izquierdo encontramos varias notas. Una especie de «A» en marrón y sobre ella, en letra humanística bastarda y tinta negra «Generales». A su izquierda «Caxón de/ pechos, derechos, etc./ Azémilas». Debajo, en marrón y humanística redonda «25./ Confirmación fecha por el rey/ don Alonso de la [pos]essión de la mitad/ de los pechos y derechos de los vassallos/ de los lugares de la Orden./ Fecho a X de agosto, era $\mathrm{M} / \mathrm{CCCLV}$ ». En la plica, bajo los vínculos, el número «27»y, a su derecha, «D. Soror». En el borde derecho la cifra «6» en marrón oscuro. 
Cit.: AHN, OM, Ind. 1, f. 28v. AHN, OM, Ind. 2, f. 123r y 193v. AHN, OM, Ind. 5, f. 41v. AHN, OM, Ind. 162, p. 72. AHN, OM, Ind. 181, n ${ }^{\circ} 1$ y no 7. AHN, OM, Ind. 182. AHN, OM, Ind. 227, f. 9v. Regla y establecimientos, f. $36 r$.

Reg.: Gutiérrez del Arroyo, Privilegios reales, doc. no 641, p. 273.

[S] epan quantos este nuestro privillegio vieren cómmo nos, don Alffonsso, por la graçia de Dios, rey de Castiella, de Toledo, de León, de Gallizia, de Sevilla, Córdova, de Murçia, de Jahén, del Algarbe et sennor de Molina,/ viemos un privillejo rodado del rey don Fernando, nuestro padre, que Dios perdone, seellado con su seello de plomo en que estava escripto su nonbre con su mano, fecho en esta guisa:

(Aquí se inserta un privilegio de Fernando IV -1302, noviembre, 20. Valladolid-)

Et porque don Garçi Fernández, maestre que es agora de la cavallería de la dicha orden de Santiago, nos en-/ bió pedir por merçed quel conffirmássemos este privillegio, nos, por fazer bien et merçed a él et a los otros maestres que después dél vinieren por muchos serviçios que la dicha Orden faze a los reyes onde nos veni- ${ }^{33}$ mos et faze agora a nos, con conssejo et con otorgamiento de la reyna donna María, nuestra avuela, et del inffante don Johán et del inffante don Pedro, nuestros tíos et nuestros tutores et guarda de los nuestros regnos,/ tenémoslo por bien, otorgamos este privillegio et conffirmámoslo et mandamos que vala segund que mejor et más conplidamiente valió en tienpo del rey don Fernando, nuestro padre, que Dios perdone, et en el/ nuestro fasta aquí.

Et deffendemos firmemiente que ninguno non sea osado de yr nin de passar contra él para lo menguar nin para lo quebrantar en ninguna manera, si non qualquier o qualesquier que lo fiziessen a- ${ }^{\beta 6}$ vríe nuestra yra et pecharnosya en coto la pena de los diez mill maravedís sobredichos et al maestre et a la Orden sobredicha, o a quien su boz toviesse, todo el danno et el menoscabo que por ende reçibiesse,/ doblado. Et porque esto sea firme et estable, mandamos seellar este privillegio con nuestro seello de plomo.

Fecho el privillegio en Córdova, diez días de agosto, era de mill et trezientos e cinqu-/ enta et çinco annos.

Et nos el sobredicho rey don Alffonsso, regnante en Castiella, en Toledo et en León, en Gallizia, en Sevilla, en Córdova, en Murçia, en Jahén, en Baeça, en Badajoz, en el ${ }^{\beta 9}$ Algarbe et en Molina, otorgamos este privillegio et conffirmámoslo. 
Johán Rodríguez de Sesenna, camarero mayor del inffante don Pedro et chançeller del rey de las sus cartas blancas que don Pedro/ trae, lo mandó fazer por mandado del rey et de los sus tutores.

Yo, Martín Domínguez, lo fiz escrevir en el anno quinto que el rey sobredicho regnó./

Johán Rodríguez, vista (rúbrica). Martín Domínguez (rúbrica).

(S.P.D.)

1318, noviembre, 8. Toledo.

Alfonso XI confirma al maestre y orden de Santiago los privilegios y exenciones de pechos otorgados por él, Fernando IV y Sancho IV.

A. AHN, OM, Uclés, carp. 2, vol. I, $\mathrm{n}^{\circ}$ 22. Pergamino rectangular de 428 $\mathrm{mm} \times 380 \mathrm{~mm}+67 \mathrm{~mm}$. Márgenes: superior $33 \mathrm{~mm}$, izquierdo 30 $\mathrm{mm}$, derecho $5 \mathrm{~mm}$ e inferior $32 \mathrm{~mm}$. Entre renglones la separación es de $3 \mathrm{~mm}$. La calidad de la materia es buena, muy gruesa pero está en regular estado de conservación. Presenta pequeñas manchas de humedad y algunos pliegues, especialmente en los márgenes, que han provocado que se rasgue el documento. También se observan varios agujeros en la zona central y junto a una de las rúbricas, dificultando, en algunos puntos, la lectura del texto. Plica con tres orificios romboidales, sin restos de los vínculos ni del sello de plomo. Tinta ocre oscura y letra gótica minúscula documental tipificada. La suscripción del escribano está realizada en gótica cursiva de «albalaes» y tinta marrón.

Notas archivísticas: centrado en las espaldas del pergamino, con tinta color marrón oscuro y grafía humanística redonda, subrayado «Privilegios Generales» y a continuación «Caxón 2,/ volumen 1,/ núm. 22». Sobre esta nota, en bastardilla redonda «Era 1356. Año 1318» y al lado, con tinta negra y de menor módulo "Uclés. 43». En letra del siglo xx y tinta azul «1318, noviembre, 8». En el margen izquierdo se hallan varias anotaciones en color ocre y grafía de tendencia cortesana, ilegibles en su mayor parte: «[...] prior y convento». Debajo, «Del maestre de Santiago». En el margen derecho, en humanística corriente y tinta negra «Convento de/ Uclés». Al lado, ilegible el resumen del documento, tan sólo apreciamos «[...] de las esen-/ [...]» en tinta oscura. En letra del siglo XVII y tinta ocre algo desvaída «El rey don Alonso, confirmación./ Convento de Uclés». 
B. AHN, OM, Uclés, carp. 5, vol. I, nº 52. Inserto en un privilegio rodado de Juan II (1430, diciembre, 6. Valladolid). Pergamino y letra gótica textual.

Cit.: AHN, OM, Ind. 3. AHN, OM, Ind. 4, f. 92v y 25r. AHN, OM, Ind. 5, f. 3v. AHN, OM, Ind. 162, p. 10. AHN, OM, Ind. 227, f. 2 r.

EDIT.: Bulario Santiago, p. 382.

Reg.: Gutiérrez del Arroyo, Privilegios reales, doc. no 644, p. 274.

Sepan quantos essta carta vieren cómmo yo, don Alffonso, por la gracia de Dios, rey de Casstiella, de Toledo, de León, de Gallizia, de Seviella, de Córdova, de Murçia, de Jahén, del Algarbe e sennor de Molina,/ vi una carta mía en papel fecha en essta guissa:

«Porque yo e la reyna donna María, mi avuela, e las ${ }^{40}$ inffantes don Johán e don Pedro, míos tíos e míos tutores, vimos una carta del rey don Fernando,/ mío padre, que Dios perdone, fecha en essta guissa:

(Aquí se insertan cartas de Fernando IV -1302, abril, 15. Valladolidy Sancho IV -1282, agosto, 7. Treviño-)

E yo, el sobredicho/ rey don Alffonsso, con conssejo e con otorgamiento de la reyna donna María, mi avuela, e del inffante don Johán e del inffante don Pedro, míos tíos e míos tutores, e porquel/24 dicho fray Pay Rodríguez, prior sobredicho, me lo enbió pedir por merçed, conffírmol essta carta e mando que vala e le sea guardada en todo bien e conplidamente. E ninguno non/ sea ossado de ge la menguar nin de ge la quebrantar nin le passar contra ella so la pena sobredicha que en ella se contiene. E sobressto mando a todos los aportellados, a cada/ unos en sus logares, [que ge lo fagan] anssí guardar e conplir e non conssientan a ninguno que les passe contra ello. $\mathrm{E}$ non fagan ende al so la pena sobredicha. E dessto le ${ }^{27}$ mandé dar essta mi carta seellada con mi seello.

Dada en Guadalffajara, diez días de enero, era de mill e trezientos e cinquenta e tress annos.

Yo, Bartolomé Gómez, la fiz/ escrevir por mandado del rey e de la reyna donna María, su avuela, e del inffante don Johán e del inffante don Pedro, sus tíos e sus tutores.

Roy García. Gonçalo Pérez.»/

40 Así por «los». 
E agora don fray Garçía Pérez, prior de Uclés, enbióme pedir por merçed que yo quel mandasse otorgar e conffirmar essta carta de libertad e de franqueza que los reyes sobredichos ${ }^{\beta 0}$ onde yo vengo fizieron, e les confirme a él e a los que fueren priores de Uclés e canónigos de su convento de aquí adelante desspués de sus días. E yo, con conssejo e con otor-/ gamiento de la reyna donna María, mi avuela, e del inffante don Johán e del inffante don Pedro, míos tíos e míos tutores e guarda de míos regnos, otórgogela e conffír-/ gela ${ }^{41}$ e mando quel sea guardada a él e a todos susçessores e canónigos.

E mando a todos los aportellados, anssí eclesiássticos commo seglares, que ninguno non sea ossado/ ${ }^{33}$ de yr contra essta libertad e franqueza que yo fago al dicho don frey Garçía Pérez, prior de Uclés, e canónigos e a los que desspués dellos vinieren. E qualquier que contra essto/ viniesse o viniere, pecharmeya en pena mill maravedís de la buena moneda nueva e al dicho prior e canónigos e a los que desspués dellos vinieren todo el danno e el menosscabo que por/ ende reçibiessen, doblado. E de essto le mandar ${ }^{42}$ essta mi carta seellada con mi seello de plomo.

Dada en Toledo, ocho días de novienbre, era de mill e trezientos e/ çincuenta e seys annos.

Yo, Martín Domínguez, la fiz escrevir por mandado del rey e de sus tutores.

Pero Martínez, vista. Johán Miguel. Domingo Ferrández. Johán García (rúbricas).

(S.P.D.)

41 Así por «confirmógela».

42 Así por «mandé dar». 